\section{Case Reports in Ophthalmology}

Case Rep Ophthalmol 2021;12:68-72

DOI: 10.1159/000510818

Published online: January 14, 2021
(C) 2021 The Author(s)

Published by S. Karger AG, Basel www.karger.com/cop

\title{
Modified Loop Myopexy (Yokoyama's Procedure) for High Myopic Strabismus Fixus
}

\author{
Patricia Ann L. Lee Shinjiro Kono Hirohiko Kakizaki \\ Yasuhiro Takahashi \\ Department of Oculoplastic, Orbital and Lacrimal Surgery, Aichi Medical University \\ Hospital, Nagakute, Japan
}

\section{Keywords}

Loop myopexy · High myopic strabismus fixus - Lateral canthotomy and cantholysis - Upper conjunctival fornix incision

\begin{abstract}
In the classic loop myopexy (Yokoyama) procedure, muscle belly union in the deep orbit is technically difficult, particularly in patients with deep-set eyes and narrow palpebral fissures. Our modified procedure includes a lateral canthotomy and cantholysis and upper conjunctival fornix incisions to facilitate this step.

(C) 2021 The Author(s)

Published by S. Karger AG, Basel
\end{abstract}

\section{Introduction}

Loop myopexy for high myopic strabismus fixus was first reported by Yokoyama and colleagues [1-3]. In the original procedure, the superior and lateral rectus muscles are sutured together approximately $15 \mathrm{~mm}$ posterior to their insertions [1-3]. Suturing at such a deep point in the orbit is technically difficult, particularly in patients with deep-set eyes and narrow palpebral fissures.

To facilitate muscle belly union, we modified loop myopexy to include a lateral canthotomy and cantholysis as well as upper conjunctival fornix incisions.

Yasuhiro Takahashi
Department of Oculoplastic, Orbital and Lacrimal Surgery
Aichi Medical University Hospital
$1-1$ Yazako-Karimata, Nagakute, Aichi 480-1195 (Japan)
yasuhiro_tak@yahoo.co.jp




\section{Case Reports in Ophthalmology}

\section{Case Report}

A 69-year-old woman with bilateral high myopic strabismus fixus (Fig. 1a) consulted us for the correction of strabismus in her left eye. Best corrected visual acuity was $30 \mathrm{~cm} / \mathrm{CF}$ in the right eye and 0.02 in the left eye. While the refractive error could not be measured in the right eye, the left eye had $-9.75 \mathrm{D}$ of spherical power and $-2.00 \mathrm{D}$ of cylindrical power. The patient showed left eye dominance; had deep-set eyes with narrow palpebral fissures on both sides; exhibited extremely limited extraocular movement in all fields of gaze in both eyes (Fig. 1a); and had Hertel exophthalmometric values of 11 and $12 \mathrm{~mm}$ (with a base of $86 \mathrm{~mm}$ ) in the right and the left eye, respectively. Computed tomography (CT) images showed superotemporal protrusion of the elongated eyes with inferior and nasal displacement of the lateral and the superior rectus muscle, respectively (Fig. 1b). The axial globe length measured on CT was $30.5 \mathrm{~mm}$ in the right eye and $31.0 \mathrm{~mm}$ in the left eye.

Surgery was performed under general anesthesia and by an oculoplastic surgeon (Y.T.) with the aid of binocular loupes and a headlight (high-resolution prismatic HRP $\times 2.5,340$ mm/13 inches; Heine, Herrsching, Germany). A 15-mm skin incision was made along the lateral canthal rhytid (Fig. 2a). The upper and lower crura of the lateral canthal support system were cut. The underlying periosteum was incised to expose the lateral orbital wall, the inner angle of which was removed with a Kerrison rongeur (Fig. 2b). The shallow part of the lateral orbital wall at the same level of the globe was also removed using an ultrasonic bone aspirator (Sonopet ${ }^{\circledR}$ UST-2000; Stryker Japan, Tokyo, Japan). A radial conjunctival incision was made at the 4-o'clock position, beginning from the lateral canthotomy area to the corneal limbus, to expose the lateral rectus. The upper conjunctival fornix was then incised from the lateral canthotomy area to expose the superior rectus. The resulting conjunctival flap was reflected onto the cornea (Fig. 2c). Muscle hooks were used to isolate and secure the lateral and superior rectus muscles. Suturing points $15 \mathrm{~mm}$ posterior to both muscle insertions were measured using a caliper, and marked (Fig. 2d, e). The muscles were then sutured with 5-0 Prolene ${ }^{\circledR}$ sutures (Fig. 2f). The conjunctiva was closed with 8-0 Vicryl ${ }^{\circledR}$ sutures. After suturing the periosteum and repositioning the lateral canthus with 5-0 PDS II ${ }^{\circledR}$ sutures, a lateral canthoplasty was performed with a 6-0 PDS II ${ }^{\circledR}$ suture. The orbicularis oculi muscle and skin were sutured with 6-0 PDS II ${ }^{\circledR}$ sutures (Fig. 2g).

Postoperative CT images showed repositioning of the left globe. At 3-month follow-up, the left eye remained well positioned and exhibited improved extraocular muscle motility. No complications such as globe rupture, retinal detachment, ptosis, or eyelid and lateral canthal deformities were noted.

\section{Discussion}

The classic loop myopexy (Yokoyama) procedure utilizes an eyelid speculum and a conjunctival incision along the corneal limbus to expose the superior and the lateral rectus muscle. However, these steps do not allow the surgeon to widely open the eyelids or easily manipulate structures in the posterior orbit, especially in patients with deep-set eyes and narrow palpebral fissures, like in our patient. We modified Yokoyama's procedure to create a wider surgical field by adding a lateral canthotomy and cantholysis, which exposed the deeper part of the lateral rectus, and an upper conjunctival fornix incision, which more efficiently exposed

\section{Karger'=}




\section{Case Reports in Ophthalmology}

the superior rectus muscle insertion. These steps facilitated muscle belly union more than an incision created at the corneal limbus.

The inner edge of the lateral orbital rim and the lateral orbital wall at the level of the globe were partially removed in our patient. This widened the surgical field and allowed better access to the muscle belly union point, which shifts deeper into the orbit in patients with enophthalmos. In a previous report, improved extraocular muscle motility following orbital decompression was also noted in a patient who underwent decompression for dysthyroid optic neuropathy [4]. As such, this step also aimed to create more space for normal extraocular movement, which is especially important in a crowded orbit with an elongated eye [5]. However, since loop myopexy alone substantially improves extraocular muscle motility, lateral orbital wall decompression may not be necessary in every case. Future comparative studies are necessary to quantify the effect of orbital decompression in high myopic strabismus fixus.

In conclusion, we modified loop myopexy for high myopic strabismus fixus. This procedure is a useful option in patients with deep-set eyes and narrow palpebral fissures. However, since this procedure is also more invasive than the classic technique, its indication should be evaluated more thoroughly in such patients.

\section{Statement of Ethics}

The authors adhered to the tenets of the 1964 Declaration of Helsinki. Written informed consent from the daughter of the patient for the publication of this report was obtained (including images). We asked the institutional review board of Aichi Medical University Hospital and confirm that ethics approval for this report was not necessary on the basis of the ethical guidelines for medical and health research involving human subjects established by the Japanese Ministry of Education, Culture, Sports, Science, and Technology and the Ministry of Health, Labor, and Welfare.

\section{Conflict of Interest Statement}

The authors declare no conflicts of interest.

\section{Funding Sources}

No funding was received.

\section{Author Contributions}

All authors qualify for authorship based on contributions to the conception and design (Y.T.), acquisition of data (P.A.L.L., S.K., and Y.T.), literature search (Y.T.), and analyses and interpretation of data (all authors). All authors contributed to drafting the article and revising it critically for important intellectual content and provided final approval of the version to be published.

\section{Karger'=}




\section{Case Reports in Ophthalmology}

\begin{tabular}{l|l}
\hline Case Rep Ophthalmol 2021;12:68-72 \\
\hline DOI: 10.1159/000510818 & $\begin{array}{l}\text { ○ 2021 The Author(s). Published by S. Karger AG, Basel } \\
\text { www.karger.com/cop }\end{array}$ \\
\hline
\end{tabular}

Lee et al.: Modified Loop Myopexy

\section{References}

1 Yokoyama T, Tabuchi H, Ataka S, Shiraki K, Miki T, Mochizuki K. The mechanism of development in progressive esotropia with high myopia. In: de Faber JT, editor. Transactions of the 26th meeting of European Strabismological Association. Barcelona: Swets \& Zeitlinger Publishers; 2000. p. 218-21.

2 Yamaguchi M, Yokoyama T, Shiraki K. Surgical procedure for correcting globe dislocation in highly myopic strabismus. Am J Ophthalmol. 2010 Feb;149(2):341-6.e2.

3 Su Y, Shen Q, Fan X. Loop myopexy surgery for strabismus associated with high myopia. J Ophthalmol. 2016;2016:8657036.

4 Takahashi Y, Kakizaki H, Shiraki K, Iwaki M. Improved ocular motility after balanced orbital decompression for dysthyroid orbitopathy. Can J Ophthalmol. 2008 Dec;43(6):722-3.

5 Satchi K, McNab AA. Orbital decompression in the treatment of proptosis due to high axial myopia. Ophthal Plast Reconstr Surg. 2010 Nov-Dec;26(6):420-5.
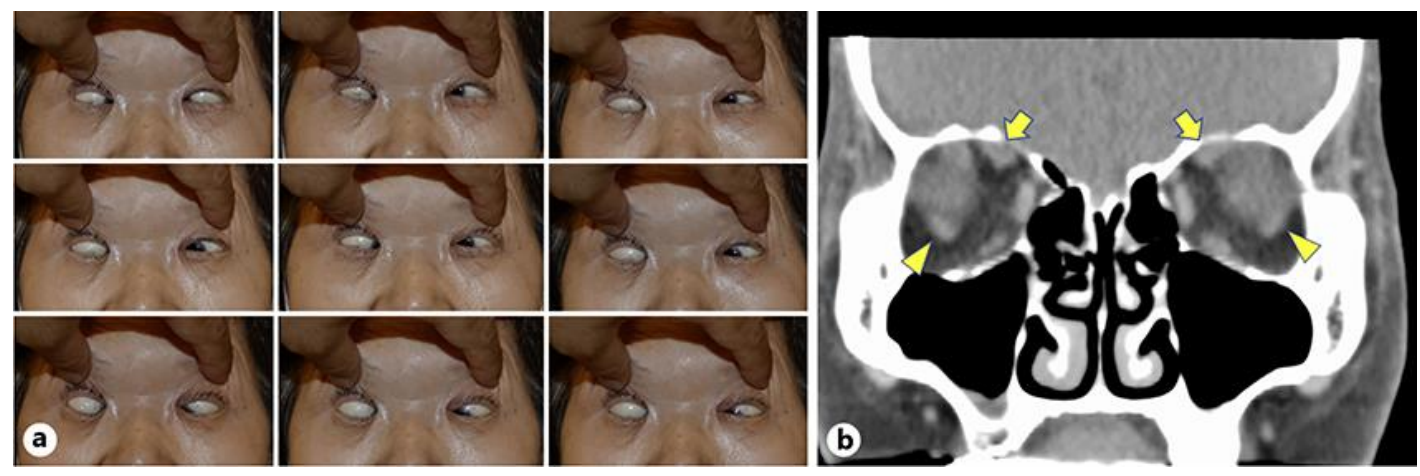

Fig. 1. Preoperative findings. a A face photo showing nine-gaze extraocular motility. Severe esotropia and extraocular muscle motility restriction in both eyes. b A coronal computed tomography image showing displacement of the lateral (arrowheads) and the superior rectus muscle (arrows). 
Case Reports in Ophthalmology

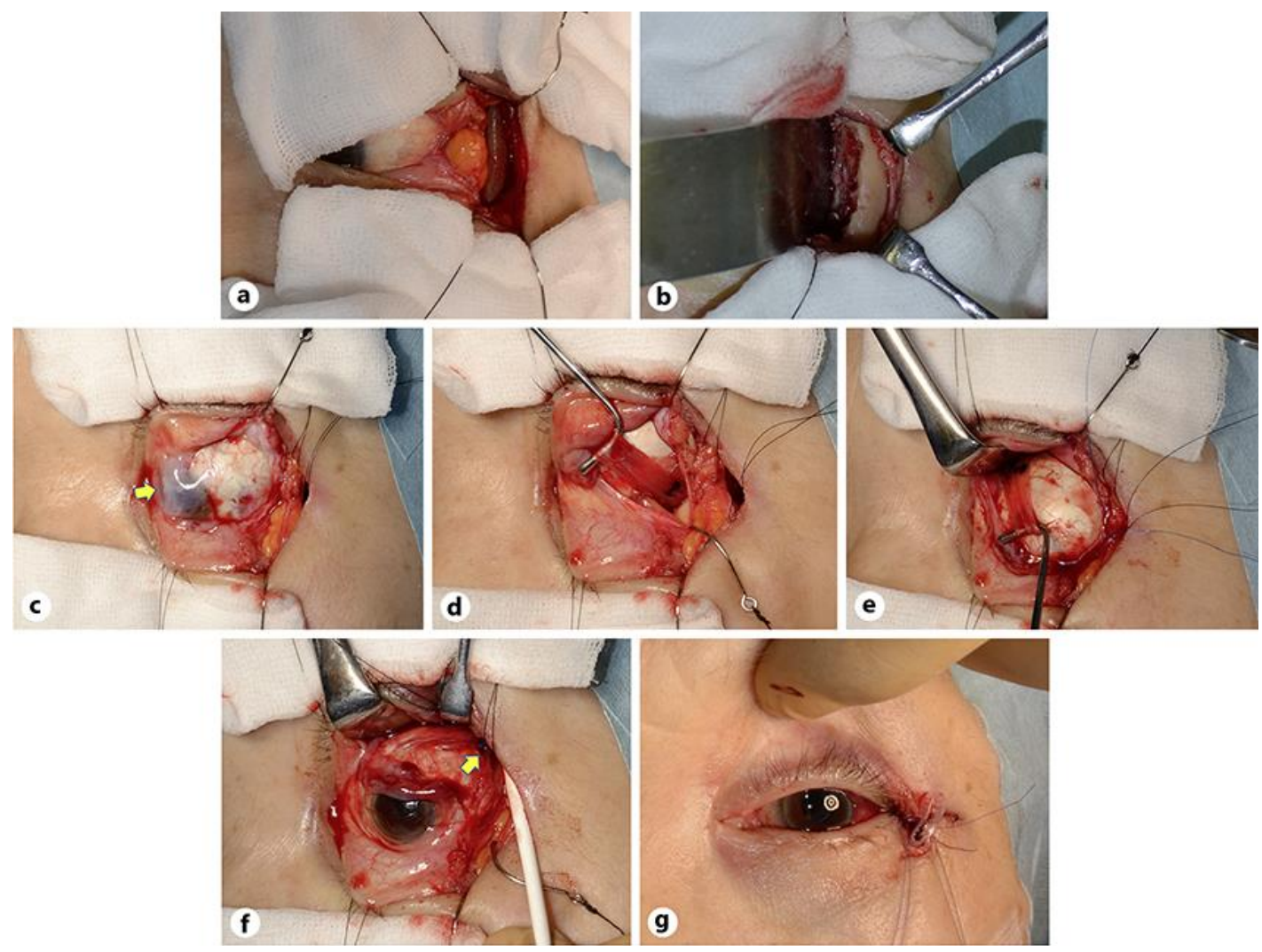

Fig. 2. Intraoperative photos. a After a lateral canthotomy and cantholysis. $\mathbf{b}$ Removal of the inner edge of the lateral orbital rim and a shallow part of the lateral orbital wall. c After a radial conjunctival incision along the inferior margin of the lateral rectus muscle and upper conjunctival fornix incision, the conjunctival flap (arrow) was reflected. d, e Marking at the points $15 \mathrm{~mm}$ posterior to the insertion of the lateral and the superior rectus muscle. $\mathbf{f}$ Muscle union (arrow). $\mathbf{g}$ After wound closure. 